\title{
CONTENTS
}

A Symposium on Indigestion. I. The Surgical AspeCt.

By H. W. Carson, F.R.C.S. • . . . 33

Antenatal Care as it Affects the Child in UTERO.

By Thomas Watts Eden, M.D., F.R.C.P., F.R.C.S.

The Conversion Neurosis.

By Ernest Snowden, M.B. 33

Notes on Post-Graduate Work in Vienna. By J. L. Meagher, M.D.
CORRESPONDENCE.

Provincial Post-Graduate Work and Publicity 48

X Ray Diagnosis.

By J. Magnus Redding, F.R.C.S. . • . 48

Editorial Notes :-Special Courses. • . . 47

Fellowship of Medicine and Post-Graduate Medical Association :-Officers, 1926-1927 • 5 Spectal Courses and Lectures

\section{A SYMPOSIUM}

ON

\section{N D I G E S T I O N.}

Being Remarks of the Opening Speakers at a Recent Discussion on this subject at the Hunterian Society.

I. THE SURGICAL ASPECT.

BY

H. W. CARSON, F.R.C.S. ENG., BENIOR SURGEON, PRINCE OF WALES'S GENERAL HOSPITAL.

Althougr there may be some difficulty in defining the word "indigestion," we do know that for the treatment of many abnormal conditions in the abdomen surgical methods are now adopted, and that justifies a surgeon in taking part in this discussion The surgery of indigestion is confined within the years of my medical life. In the year I went up to Bart.'s only 17 abdominal operations were done, excluding 13 gynæcological operations. They were all for some form of emergency and none could be fairly classed as an operation for the relief of indigestion. These emergency operațions had a mortality of 7 of the 17.

When I came down from Bart.'s in 1895, 96 abdominal operations (excluding gynæcological operations) - 69 of whom died-were done, of which only nine, by the widest stretch of the imagination, could be considered indigestion operations-namely, five cholecystotomies with two deaths, a fatal plastic operation on the pylorus for stricture, two fatal gastro-jejunostomies both for cancer, one operation on a quiescent appendix (the other nine appendix operations were all abscess cases). Thirteen operations were done on the intestines with 11 deaths. So we were only at the beginning of things then.

It is, perhaps, useless to ask why the surgeon has taken the position he has in the treatment of indigestion, but there is no doubt that with his arrival there came a demand for thorough investi- gation of conditions. It may have been purely fortuitous that the biochemist and the radiologist appeared on the scene at the same time, but it is certain that the aid of these two sciences revolutionised our powers of diagnosis in indigestion.

\section{Causation.}

Similar progress has not been made in determining the causation of indigestion. The septic theory still holds the chief place, the teeth, the nasal sinuses, the tonsils, the appendix being accused of causing gastric ulcer, duodenal ulcer, gall-stones, and so on. Of late a good deal of attention has been focusedo on our food-supply, and the old statement "Hear. and understand! not that which goeth into the mouth defileth a man" (Matt. xv., 11) is not so true in the twentieth century as in the first. There are comparatively few articles of food that are not treated by some preservative or colouring matter, and it is arguable whether the sense of well-being that comes to us after a few days in the country is not due to the fact that we are not for the moment being poisoned by food treated with boric acid or some other preservative. Eggs and milk are specially suspect. Soon the endocrinologists will begin to interest themselves in indigestion.

At the moment the surgeon is permitted to deal, as far as the stomach and duodenum is concerned, chiefly with chronic ulcer. Medicine claims to be able to cure early cases, and it is only when the patient is recalcitrant and refuses to get well when the physicians tell him to that he is thrown to the lions who gratefully accept him and do what they can for him. But this very fact proves that we surgeons ought to have no share in gastric and duodenal ulceration. If the condition is preventable or if it is curable in the early stages, what right have we surgeons to spend so much of our time operating on chronic ulcer and its complications?

Whether we have discovered the proper way to treat these conditions and whether we obtain a high enough percentage of cures with a low enough mortality to justify our interference is worth considering. 
Gastric and Duodenal Ulcer.

Are we doing the right thing for duodenal ulcer? Our results show us that with a minimal mortality (less than 1 per cent.) we restore complete digestive health to about 85 per cent. of our cases by doing a gastro-jejunostomy. But what about the balance of 14 per cent. ? A certain small proportion are made worse (there is always the bogy of gastrojejunal ulcer) and in a certain number, particularly apparently those who have had melæna, the symptoms persist. And yet with 85 per cent. cures one is hardly tempted to embark on such an operation as a duodenectomy, which may carry with it at the moment a mortality of 10 per cent.

And then there is gastric ulcer. Is the modern tendency to make a direct attack by excision or partial gastrectomy better than the older method of indirect attack by gastro-jejunostomy? I feel sure that it is, even if we agree that it is not proven that gastric ulcer is a forerunner of cancer. Gastro-jejunostomy should be reserved for lesions quite near the pylorus. I am convinced that when a chronic gastric ulcer becomes adherent anything short of a partial gastrectomy is useless and, indeed, may do more harm than good. And I am sure that all the complications of gastric ulcer, except, perhaps, hæmorrhage, should be packed off to the surgeon right away.

But I am equally certain of this, that gastric or duodenal ulcer is not a simple isolated fortuitous happening, but that it is a manifestation of some systemic disorder, such as a toxæmia, and that the operation is only one part of the treatment which should have begun by systematic search for, and remedy of, any septic focus and have finished by a course of treatment and dieting for several months.

By the way, it is curious how diseases vary. In my student days the appropriate disease for the brain workers was angina pectoris; now it is duodenal ulcer. Is it possible that some of those angina cases were really indigestion which can now be diagnosed by modern methods?

\section{Cholecystitis and Gall-stones.}

When we consider cholecystitis and gall-stones we come to the curious position that a section of medical men believe that they can best be treated by drugs. It is a strange belief and entirely unjustified, but it is widely held, although I have never heard a physician claim that he could cure stone in the bladder or kidney or even in the submaxillary duct by medicine. I suppose what weighs is a recollection of the time when operations on the gall-bladder were followed by a prohibitive mortality and the doctor feels he must save his patient from such a fate at all costs. I take up an unqualified attitude that cholecystitis and gallstones is surgical from the first, that operation should be refused only if the patient is too bad a surgical risk, and that gall-stones treated by any other means than surgery may be responsible for many dangerous complications. Our real trouble with gall-stones is the diagnosis. More diagnostic mistakes are made over this disease than over any other intra-abdominal lesion. The Meltzer-Lyon test has not helped us as we hoped; $\mathrm{X}$ rays demonstrate only about 10 per cent. Perhaps the new dye method will be more valuable.

\section{INDIGESTION AND CANCER.}

Now we come to a very important question. It is indigestion due to cancer in the gastrointestinal tract. It is almost certain that cancer of the stomach is increasing in frequency and cancer of the colon is fairly common. But it is a regrettable fact that both these conditions usually come to the surgeon too late. The operability of cancer of the stomach is not much over 25 per cent., and of my whole series of cases of cancer of the colon just half were obstructed when first seen, and in only 40 per cent. have I been able to attempt a radical cure. This means that the profession either does not know or is not taught the early signs of either of these diseases, and thus we see stomach cancer with a big tumour and persistent vomiting, and colon cancer in obstruction. My rule should be that indigestion occurring in a patient over 50-occurring. for the first timeshould be considered to be due to cancer unless the opposite can be proved. Cancer in either of these regions is not difficult to diagnose, the trouble being that it is not suspected until it becomes too obvious.

In so vast a field it is impossible to do more nowo than refer to a few subjects. I wish to say a word or two about

\section{Right-sided Abdominal Pain.}

There is still great tendency to associate all pain in the right iliac fossa with appendicitis and with all our care we immediately think of appendicitis when a patient comes complaining of this symptom. Now the chronic appendix does not always or often give rise to pain in this region, but causes epigastric pain which may very closely simulate gastric or duodenal ulceration. The result of this belief in the relation of pain in the right iliac fossa to appendicitis is that an enormous number of appendices are removed every year for conditions of which it is not the cause, and no benefit results.

The lateral incision for appendectomy does not permit of an adequate exploration of the abdomen. I operated for gastric ulcer a short time ago on a patient whose appendix had been removed through a minute incision just above Poupart's ligament (Sonnenburg's incision). The patient was told by his surgeon that a thorough exploration had been done and nothing else had been discovered! Many articles have been written on failure to cure after removing the appendix, the best of which perhaps was by Bettman, of Cincinatti, ${ }^{1}$ and Eastman ${ }^{2}$ wrote an article entitled "Chronic Appendicitis : Is it a Myth?" Well, I am sure it is not a myth, but I think we should be well advised rarely to

\footnotetext{
1 Jour. Amer. Med. Assoc., 1924, vol. Ixxxiii., p. 1216.
} surg., Gyn., Obstr., January, 1924 . 
diagnose it in the absence of a history of severe attack and never for right iliac fossa pain only.

\section{VISCEROPTOSIS.}

The last subject I will mention is visceroptosis, and this will, perhaps, gently lead the way for Dr. Crichton Miller, for many of these cases have neurasthenic associations. By visceroptosis I mean a condition of undue mobility of the abdominal organs associated with pain and disordered action of the stomach and intestines. It is almost confined to women and is undoubtedly accompanied by, and probably the cause of, a great deal of invalidism.

A great stimulus has been given to the study of visceroptosis by the exact method of observation -obtained by $\mathrm{X}$ ray examination after a barium meal, and the difficulty we had to contend with at first was that the normal was not properly known and many variations from the normal were considered pathological, that now, thanks to the researches of Dr. J. A. Ryle and others, we know to be compatible with perfect function. We have now given up believing that because a patient's hepatic flexure is normally below the level of the iliac crest in the standing position that any harm need result, and the normal haustrations of the transverse colon are no longer believed to be evidence of " catarrh." A stomach may be hypertonic or hypotonic and still be normal for that type of individual.

This change of opinion has necessarily been followed by a change in our practice, and operations for reefing and suspending the stomach are practically abandoned, and I hope that fixing the ascending colon, short circuiting the colon, and excision of the colon for stasis will soon be abandoned also. We must remember that all the abdominal organs should be capable in health of some degree of movement, and the fixation of, say, a kidney or the cæcum is contrary to the laws of nature and is, therefore, wrong in principle.

I believe we shall agree sooner or later that operations to fix what should be mobile organs are not successful, and that if operations must be done the indication is rather to free organs abnormally fixed, say, by adhesions, than to fix abnormally free.

(The opening remarks on the Mental Aspect of the question will be published in our next number.-ED.)

DURING October there was a goodly list of new subscribers to the Post-Graduate Medical JoURnal, including, in addition to those resident in Great Britain and Ireland, others practising in Canada, and in America, in India, South Africa, Egypt, New Zealand, and no fewer than eight in Burma. One applicant writes from Ontario : "I am glad to know of all the possibilities of postgraduate studies, as I was contemplating crossing the Atlantic for some post-graduate work somewhere in Britain. . . . I am intensely interested in the fact of the arrival of the JournaL, and shall look forward to each number, which will make me more conversant with the possibilities of certain courses in the Old Land."

\section{ANTENATAL CARE} AS IT AFFECTS THE CHILD IN UTERO.*

BY

\author{
THOMAS WATTS EDEN, M.D. EDIN., \\ F.R.C.P. Lond., F.R.C.S. Edin., \\ consultiNG OBSTETRIC PHYSICIAN, CHARING CROSS \\ HOSPITAL, LONDON.
}

IT is universally accepted among us that the care of infants and young children is one of the chief concerns of the State and of society. Public interest in the matter has been one of the main forces behind those developments which, in the last 25 years, have brought down our infant mortality-rate from 154 to 75 per 1000 . I am asking you on this occasion to consider to what extent we as medical practitioners are also concerned with the well-being of the child before birth. French obstetricians have for many years been much more concerned about all matters pertaining to infant mortality than we have, on account of their falling birth-rate, which has now reached a point at which the depopulation of that country may be said to have commenced. Many years ago Adolphe Pinard pointed out that in reality the preservation of child life must be considered in relation to three periods.

(1) The pre-conceptional period, in which the seed to be sown and the soil in which it is toc germinate are the elements concerned; (2) the intra-uterine period, in which development is carried from the blastomere stage up to the birth of the fully developed infant; (3) the postnatal stage.

It is Pinard's second period which concerns us -viz., that in which the child is developing in the uterus ; this period is under the care of the obstetric department of medical practice. It is, therefore, part of our duty to consider whether there is anything we can do, and if so what, to ensure that the intra-uterine child is given the best chance of completing its development and entering upon its separate existence under the most favourable possible conditions. Antenatal work should not be regarded only as a maternal safeguard, although, of course, its primary object is to ensure that the expectant mother gets through her pregnancy with the minimum of risk, and that she enters upon her labour under the most favourable obstetrical conditions.

The question I am asking you to consider is to what extent can antenatal care of the mother influence the well-being of the child in utero, Can we in any degree safeguard it against the risks of intra-uterine death or against premature expulsion, either when non-viable or later on when viable but heavily handicapped by prematurity, or from grave defects of development,

* Post-graduate Lecture delivered at the Prince of Wales's General Hospital on July 19th, 1926. 